Skeletal muscle regeneration has been induced by injection of the myotoxic drug bupivacaine (Marcaine) into the rat tibialis anterior muscle. Doses of 1.5 and $1.0 \% \mathrm{wt} / \mathrm{vol}$ produce significant levels of muscle regeneration, but these doses also produce large regions of ischemic muscle. Doses of 0.75 and $0.5 \%$ bupivacaine are also effective in inducing regeneration and produce little or no ischemia. Regenerating muscle is significantly more active in the incorporation of ${ }^{35} \mathrm{~S}-$ methionine into protein than is control muscle, and the activity increase is directly proportional to the bupivacaine dose injected. Polyribosomes were isolated in greater yield from bupivacaine-treated muscles, as compared with control muscles, 5 days postinjection, and were also more active in cell-free protein synthesis than control polysomes. Again, the yield and activity of the muscle polysomes was directly proportional to the bupivacaine concentration used for injection. Polyacrylamide gel electrophoresis of polysomal cellfree reaction mixtures demonstrated the synthesis of a number of myofibrillar proteins.

MUSCLE \& NERVE $\quad 5: 281-290 \quad 1982$

\title{
PROTEIN SYNTHESIS IN BUPIVACAINE (MARCAINE)-TREATED, REGENERATING SKELETAL MUSCLE
}

\author{
GEORGE H. JONES, PhD
}

Bupivacaine (Marcaine) is a myotoxic drug which was introduced clinically for use as a local anesthetic. ${ }^{16}$ Since its introduction, bupivacaine has been applied to the study of skeletal muscle regeneration. It has been shown by Hall-Craggs, ${ }^{8}$ by Carlson and Gutmann, ${ }^{6}$ and others, ${ }^{2.9}$ that the injection of bupivacaine into an appropriate skeletal muscle leads to a rapid and striking degeneration of that muscle which is followed by an equally dramatic regeneration phenomenon. The bupivacaine injection procedure is simple and quick, does not involve extensive surgery, and induces a regeneration process which is qualitatively similar to that observed in other model systems. ${ }^{7}$

Previous studies from this laboratory have been concerned with the direct effects of bupivacaine on macromolecular synthesis in skeletal muscle. The

From the Department of Cellular and Molecular Biology, Division of Biological Sciences, The University of Michigan, Ann Arbor, Ml.

Acknowledgment: This research was supported by grant number PCM7904260 from the National Science Foundation.

Address reprint requests to Dr. Jones at the Department of Cellular and Molecular Biology, Division of Biological Sciences, The University of Michigan, Ann Arbor, Ml 48109.

Received for publication July 31, 1981; revised manuscript accepted for publication November 19, 1981

0148-639x/0504/0281 $\$ 01.25 / 0$

(c) 1982 John Wiley \& Sons, Inc drug has been shown to be a translational inhibitor which acts primarily at the level of the aminoacylation of transfer RNA (tRNA). ${ }^{10}$ This inhibitory effect appears to be specific for eukaryotic cells and, in terms of mechanism, involves the competitive inhibition of the acylation of tRNA with leucine and certain other amino acids. ${ }^{11}$ While these observations may be related to the ability of the drug to induce muscle breakdown, they provide no information on the biochemical changes which accompany the regeneration process. Indeed, few biochemical studies have been performed on regenerating skeletal muscle. Several years ago, Wagner et al. ${ }^{17}$ demonstrated that there are changes in the specific activities of a number of enzymes involved in energy metabolism during the process of bupivacaine-induced skeletal muscle regeneration. Essentially nothing is known about the changes in macromolecular synthesis which occur during regeneration.

Because of the paucity of available information regarding the biochemical and molecular changes which take place during skeletal muscle regeneration, a thorough analysis of the translational apparatus in regenerating muscle has been undertaken. The present report examines the synthesis of proteins by muscle fragments and by polyribosomes isolated from control and regenerating muscle. 


\section{MATERIALS AND METHODS}

Materials. Bupivacaine-HCl (Marcaine) was generously supplied by Dr. A. E. Soria, SterlingWinthrop Research Institute, Rensselaer, NY. ${ }^{35} \mathrm{~S}$-methionine (760 to $\left.1160 \mathrm{Ci} / \mathrm{mmole}\right)$ and ${ }^{3} \mathrm{H}$ phenylalanine (17 Ci/mmole) were from Amersham (Arlington Heights, IL), while polyuridylic acid (poly U) was from Miles (Elkhart, IN).

Bupivacaine Injection Procedure. The technique used to induce muscle regeneration was similar to that described by Hall-Craggs. ${ }^{8}$ A solution of bupivacaine $(0.6 \mathrm{ml}$ of $0.5,0.75,1.0$, or $1.5 \% \mathrm{wt} / \mathrm{vol}$ in $0.9 \% \mathrm{NaC} 1$ ) was injected into the tibialis anterior of one hind limb of a 250 - to 350 -gm male rat using a 22-gauge needle and a 1-cc syringe. The animals were held under mild ether anesthesia during injection. The needle was inserted near the base of the muscle and advanced through the belly to the tibial plateau. The needle was slowly withdrawn while $0.2 \mathrm{ml}$ of the drug solution was injected. The needle was reinserted at a slightly different position along the distal portion of the tibialis and the injection procedure repeated with $0.2 \mathrm{ml}$. The final $0.2-\mathrm{ml}$ portion was injected after reinsertion of the needle into a third position along the distal end of the muscle. The tibialis anterior of the other hind limb was injected with $0.6 \mathrm{ml}$ of $0.9 \% \mathrm{NaCl}$ using the same procedure and served as a contralateral control. Animals were killed and muscles excised 5 days following injection. The animals and the appropriate muscles were weighed so that muscle wet weight/body weight ratios could be calculated for control and bupivacaine-injected muscles.

For the complete set of experiments, a total of 87 rats were used. Control muscles were obtained from all 87 animals, whereas bupivacaine-injected muscles were obtained from 28 ( $1.5 \%$ dose), 17 $(1.0 \%), 19(0.75 \%)$, and 23 rats $(0.5 \%)$.

\footnotetext{
Measurement of Protein Synthesis Using Muscle Fragments. Freshly excised control or bupivacaine-treated skeletal muscles were minced finely with scissors and 0.5 to $1.0 \mathrm{gm}$ of muscle was placed in 125-ml Erlenmeyer flasks with $4.5 \mathrm{ml}$ of Krebs-Ringer bicarbonate buffer, pH 7.4, containing $10 \mathrm{mM}$ glucose and $0.5 \%$ bovine serum albumin. To this preparation was added $0.5 \mathrm{ml}$ of a solution of the 19 common amino acids (minus methionine). The final amino acid concentrations in the reaction mixture were equivalent to those found in rat plasma. ${ }^{14}$ Fifty microcuries of ${ }^{35} \mathrm{~S}$ methionine were then added and the fragments were incubated with shaking for 60 minutes at
}

37 C. At the end of this incubation period, the fragments were washed twice by centrifugation in $10 \mathrm{ml}$ of Hank's solution, and were then treated with $5 \mathrm{ml}$ of $10 \%$ trichloroacetic acid (TCA) containing $3 \% \mathrm{wt} / \mathrm{vol}$ of a casein hydrolysate (Casamino acids, Difco Laboratories, Detroit, MI). The fragment mixture was heated for 10 minutes at $90 \mathrm{C}$ to destroy aminoacyl-tRNA and the fragments collected by low-speed centrifugation. They were washed 3 times with TCA-casamino acids, and 3 times with ethanol-ether $(1: 1 \mathrm{vol} / \mathrm{vol})$. The resulting protein precipitate was dissolved in 3 to 4 $\mathrm{ml}$ of $0.5 \mathrm{~N} \mathrm{NaOH}$ by heating for 10 minutes at $70 \mathrm{C}$. Aliquots of the protein solutions were neutralized with $1 \mathrm{~N}$ acetic acid and examined by liquid scintillation counting. The protein concentrations of the solutions were also determined, and results of these experiments are expressed below as cpm ${ }^{35} \mathrm{~S}$-methionine incorporated $/ \mathrm{mg}$ protein.

Preparation of Polyribosomes and Soluble Enzymes. Freshly excised muscle was weighed, minced finely with scissors, suspended in 5 volumes of Buffer 1 (50 mM TRIS-HCI, pH 7.6, $10 \mathrm{mM} \mathrm{MgCi}_{2}, 300$ $\mathrm{mM} \mathrm{KCl,} 5 \mathrm{mM}$ 2-mercaptoethanol, $10 \%$ glycerol) and homogenized in a Polytron tissue homogenizer (Brinkman Instruments, Westbury, NY) at a rheostat setting of 2. Homogenization was for $60 \mathrm{sec}-$ onds in two 30-second bursts. The homogenate was centrifuged for 15 minutes at $20,000 \mathrm{~g}$, and the supernatant was brought to $1.5 \%$ (vol/vol) with Nonidet P-40 (Shell Chemicals, Houston, TX). The detergent-treated supernatant was allowed to sit on ice for 10 minutes and was then placed in a centrifuge tube above a 4-ml cushion of $1.5 \mathrm{M}$ sucrose in Buffer 1 without glycerol. Centrifugation was for 5 hours at $200,000 \mathrm{~g}$ and $4 \mathrm{C}$. The resulting polysome pellets were rinsed quickly in cold distilled water and resuspended with gentle stirring in Buffer $2(50 \mathrm{mM}$ TRIS$\mathrm{HCl}$, pH 7.6, $10 \mathrm{mM} \mathrm{MgCl}_{2}, 100 \mathrm{mM} \mathrm{KCl}, 5 \mathrm{mM}$ 2-mercaptoethanol) to give final concentrations of approximately $50 \quad \mathrm{~A}_{260}$ units $/ \mathrm{ml}$. Polysomes were generally used immediately for protein synthesis.

Soluble enzymes for protein synthesis were prepared from rat liver. Two grams of liver were suspended in $10 \mathrm{ml}$ of Buffer 2 and homogenized with six strokes of a motor-driven Potter homogenizer (Kontes Glass Co., Vineland, NJ). The homogenate was centrifuged for 15 minutes at $20,000 \mathrm{~g}$ and the resulting supernatant for an additional 2 hours at $200,000 \mathrm{~g}$. The $200,000 \mathrm{~g}$ supernatant 
was dialyzed overnight against two changes of Buffer 2 containing 25\% glycerol.

Conditions for Cell-Free Protein Synthesis. Reaction mixtures for protein synthesis contained the following components: TRIS-HCl, pH 7.6 (50 mM); 19 amino acids, minus methionine $(0.1 \mathrm{mM}$ each); ATP (5 mM); GTP (0.5 mM); phosphocreatine (10 $\mathrm{mM})$; creatine kinase $(0.2 \mathrm{mg} / \mathrm{ml}) ; \mathrm{KCl}(75 \mathrm{mM})$; $\mathrm{MgCl}_{2}(10 \mathrm{mM}) ; 2$ mercaptoethanol (5 mM); soluble enzymes ( $8 \mathrm{mg}$ protein $/ \mathrm{ml}$ ); ${ }^{35} \mathrm{~S}$-methionine $(200 \mu \mathrm{Ci} / \mathrm{ml})$; and polysomes $\left(0.4\right.$ to $\left.20 \mathrm{~A}_{260} / \mathrm{ml}\right)$. Reaction volume was $50 \mu \mathrm{l}$ and mixtures were incubated for 30 minutes at $37 \mathrm{C}$. Reactions were stopped by the addition of TCA-casamino acids. Protein precipitates were heated in TCA-casamino acids for 10 minutes at $90 \mathrm{C}$ and were collected on glass fiber filters. ${ }^{35} \mathrm{~S}$-methionine incorporation was determined by liquid scintillation counting. Some results are expressed as $\mathrm{cpm}{ }^{35} \mathrm{~S}$-methionine incorporated $/ A_{260}$ unit of polyribosomes present in the reaction mixture.

In some incubations, polyuridylic acid (poly U) was added to reaction mixtures as a synthetic messenger RNA. In these incubations, ${ }^{35} \mathrm{~S}$-methionine was replaced by ${ }^{3} \mathrm{H}$-phenylalanine $(200 \mu \mathrm{Ci} / \mathrm{ml})$ and the 19 amino acids were omitted. Poly $U$ was present in these reactions at a concentration of 0.5 $\mathrm{mg} / \mathrm{ml}$.

Miscellaneous Methods. Polyacrylamide gel electrophoresis of cell-free reaction mixtures was performed according to the method of Laemmli ${ }^{13}$ essentially as described previously, ${ }^{12}$ except that 7 to $15 \%$ linear gradient separating gels were used. Following electrophoresis, gels were treated as described by Bonner and Laskey ${ }^{3}$ for fluorography. Myosin heavy-chain and actin standards were run in parallel with the cell-free reaction mixtures.

Histological analysis of bupivacaine-injected muscles involved hematoxylin and eosin staining of sectioned tissue, generously performed in the laboratory of Dr. Bruce Carlson. Sucrose gradient analysis of polysomes was performed as previously described. ${ }^{15}$ Protein concentrations were determined using the Bio-Rad protein assay reagent (Bio-Rad Laboratories, Richmond, CA).

\section{RESULTS}

Histological Analysis and Wet Weights of Bupivacaine-Treated Muscle. Muscle injected with varying concentrations of bupivacaine as described above was excised and examined 5 days following the injection procedure. This point was chosen because previous studies have indicated that the muscle is actively regenerating and is free of phagocytic cells by this time. ${ }^{6-8}$ To confirm this finding in the present regeneration model, it seemed prudent to first subject the injected muscle to histological analysis. The results of such an analysis are shown in Figure 1. Figure $1 \mathrm{~A}$ shows a hematoxylin and eosin-stained cross section of the tibialis anterior injected with $1.5 \%$ bupivacaine. No surviving original muscle fibers are seen in this cross section. The dark areas are filled with late regenerating myotubes. The light area ( $\mathrm{I})$ is a region of ischemic muscle fibers. Figure 1B shows a cross section through a tibialis anterior which was injected with $0.75 \%$ bupivacaine. Essentially, all of the muscle fibers have been damaged by the drug. The dark areas again show regenerating late myotubes and several small ischemic regions (I) are also observed. Figure 1C shows a cross section of control muscle for comparison. In general, it was found that the higher doses of bupivacaine (1.0 or $1.5 \%$ ) produced significant regeneration and large regions of ischemic muscle. The $0.75 \%$ dose level induced regeneration almost as effectively as a 1.0 or $1.5 \%$ dose, but did not produce high levels of ischemia. Bupivacaine at $0.5 \% \mathrm{wt} / \mathrm{vol}$ produced essentially no ischemic muscle, but was less effective in inducing regeneration than the other doses which were tested.

Table 1 shows the effects of the bupivacaine dose on the muscle weight to body weight ratios for control and injected muscle. It can be seen that bupivacaine treatment leads to a significant decrease in the muscle wet weight 5 days following injection. Table 1 also reveals that the decrease in wet weight is dose dependent, the higher doses of the drug producing the largest weight losses. These results are similar to those which have previously been reported by Wagner et al. ${ }^{17}$ for muscle soaked in bupivacaine.

\section{Protein Synthesis by Fragments of Control and} Bupivacaine-Treated Muscle. To examine the ability of intact control and regenerating muscle to synthesize protein, the muscles were minced and incubated with ${ }^{35} \mathrm{~S}$-methionine as described in Materials and Methods. Results of typical incubations are shown in Figure 2 for control muscle and muscles injected with $0.5,0.75,1.0$, and $1.5 \%$ bupivacaine. It can be seen from the figure that the level of methionine incorporation is significantly higher in the bupivacaine-treated muscle than in controls. The results shown in Figure 2 are averages 

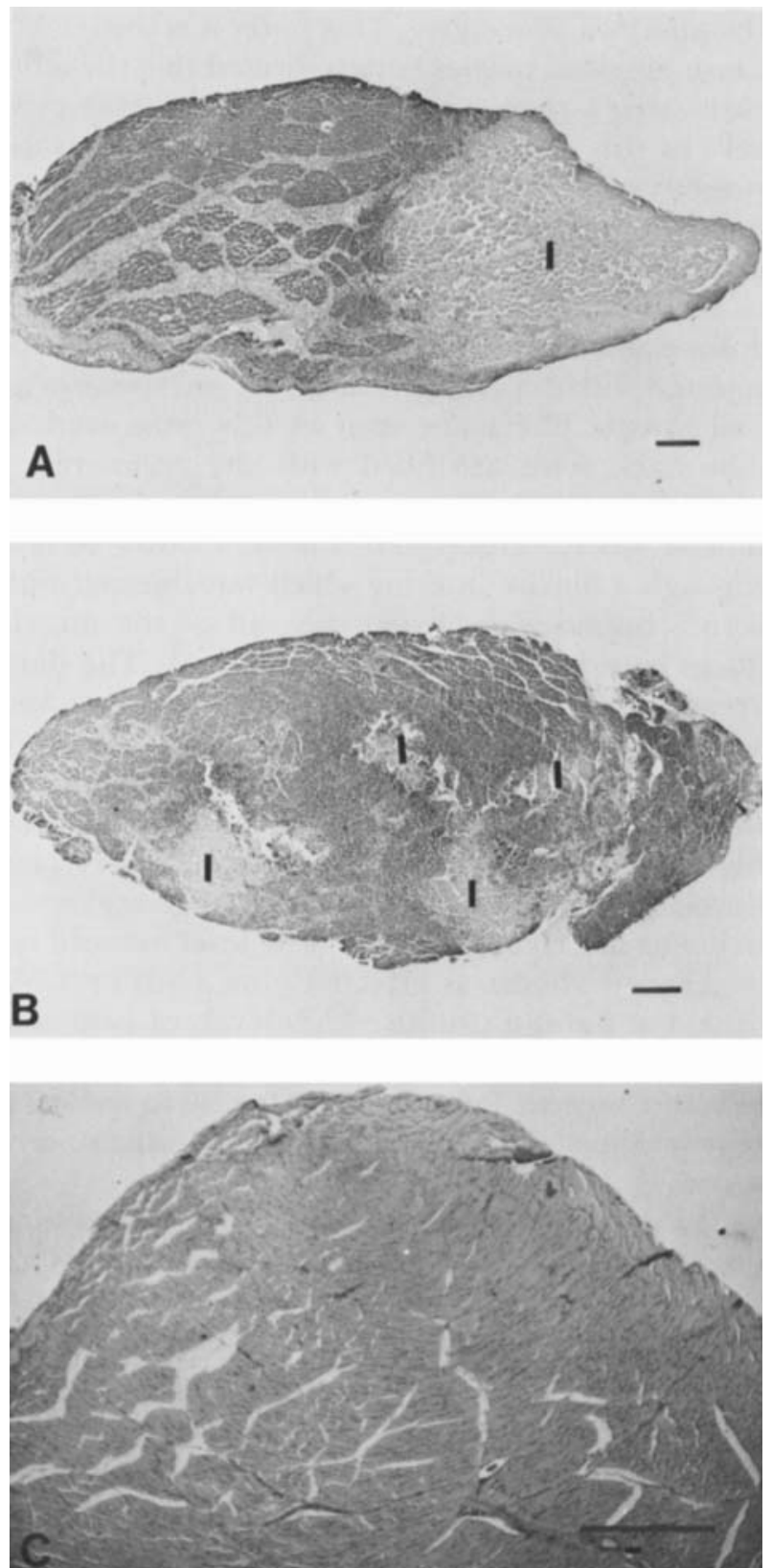

Figure 1. (A) Cross section through a rat tibialis anterior muscle 5 days after the injection of $0.6 \mathrm{ml}$ of $1.5 \%$ bupivacaine. Hematoxylin-eosin staining. (B) Cross section through a tibialis anterior muscle injected with $0.75 \%$ bupivacaine. Areas marked I show regions of ischemic muscle. (C) Cross section through a control saline-injected tibialis anterior muscle. In each micrograph, the calibration bar represents $0.5 \mathrm{~mm}$.

of those obtained in a number of experiments. Figure 2 also shows clearly that the increase in methionine incorporation was dependent on the dose of bupivacaine used for the injection. In the experiment shown, injection of $1.5 \%$ bupivacaine produced a 10.8 -fold increase in incorporation as

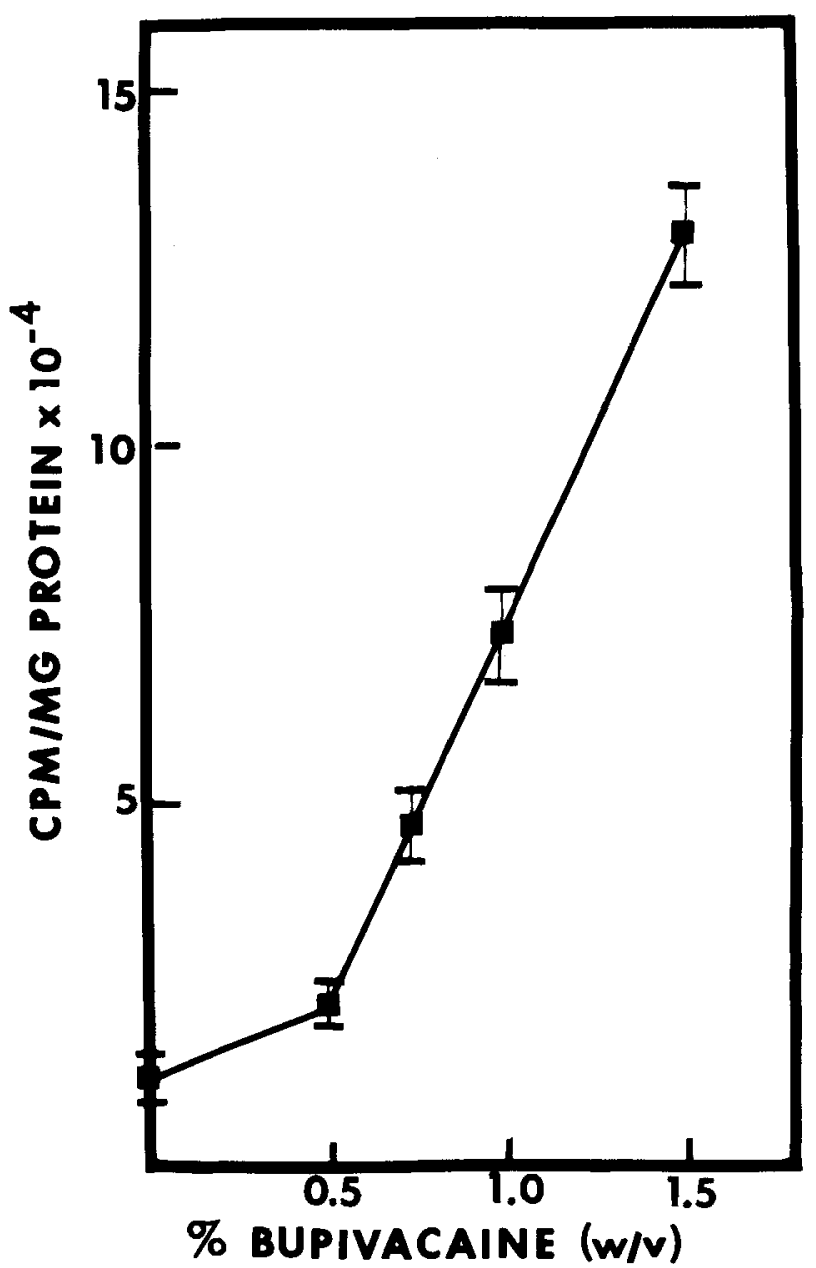

Figure 2. ${ }^{35}$ S-methionine incorporation by fragments of control and bupivacaine-treated skeletal muscle. Incubation conditions were as described in Materials and Methods. Values are means of 4 experiments $\pm S D$. Values for injected muscle differed significantly from the control at $\mathrm{P}<0.001$ at all doses. The control value is shown at zero bupivacaine concentration on the vertical axis.

Table 1. Muscle Weight to Body Weight Ratios 5 Days after Bupivacaine Treatment of Skeletal Muscle*

\begin{tabular}{lc}
\hline $\begin{array}{l}\text { Percentage of } \\
\text { Bupivacaine (wt/vol) }\end{array}$ & $\begin{array}{c}\text { Muscle Weight/ } \\
\text { Body Weight (mg/gm) }\end{array}$ \\
\hline Control & $1.60 \pm 0.13$ \\
1.50 & $1.06 \pm 0.09$ \\
1.00 & $1.14 \pm 0.23$ \\
0.75 & $1.16 \pm 0.22$ \\
0.50 & $1.22 \pm 0.13$
\end{tabular}

*Ratios were calculated using muscles from 15 animals (control), 12 animals (1.5\%), 7 animals $(1.0 \%$ ), and 8 animals $(0.75$ and $0.50 \%)$. Values are mean $\pm S D$ for the indicated number of animals. Ratios for injected muscle differed from control ratios at $\mathrm{P}<0.001$ for all bupivacaine doses. 
compared with control muscle, whereas a $0.5 \%$ bupivacaine injection resulted in a 1.8 -fold increase. As compared with controls, increases in methionine incorporation of 2- to 12-fold were routinely observed, depending on the dose of bupivacaine injected. These results suggest, not surprisingly, that skeletal muscle regeneration is accompanied by an increased synthesis of muscle proteins.

Isolation of Polyribosomes from Control and Regenerating Muscle. While the results of Figure 2 argue for an increase in protein synthesis in regenerating muscle, the data could also be explained by postulating a bupivacaine-induced change in amino acid transport into the muscle fibers or a change in amino acid pool size. To eliminate these possibilities, translational components have been isolated from control and regenerating muscle. Polyribosomes were obtained from the muscles as described in Materials and Methods. Table 2 summarizes data regarding the yields of polysomes from control and regenerating muscle. It can be seen that significantly higher quantities of polysomes were isolable from regenerating as compared with control muscle and that the polysome yields were dose dependent. The higher the dose of bupivacaine used to inject the tibialis, the higher the yield of polysomes obtained 5 days following the injection. Previous studies have indicated that skeletal muscle regeneration is accompanied by an increased synthesis of ribosomes. ${ }^{1,4}$ The increased polysome yield observed in the present study may well reflect the mobilization of these newly synthesized ribosomes for protein synthesis.

Polyribosomes were also analyzed by sucrose gradient centrifugation on 10 to $40 \%$ linear gradients. Profiles for polysomes from control and regenerating muscles were essentially indistinguishable (data not shown) and were similar to gradient profiles previously published for muscle polyribosomes analyzed in this laboratory. ${ }^{15} \mathrm{~A}_{260} / \mathrm{A}_{280}$ ratios for the polyribosome preparations varied between 1.45 and 1.60 .

Activity of Polyribosomes in Cell-Free Protein Synthesis. Polysomes isolated from control and regenerating muscle were tested for their activity as described in Materials and Methods. ${ }^{35}$ S-methionine was used as the labeled amino acid. Results of an experiment in which the concentration of polysomes in the reaction mixtures was varied are shown in Figure 3A. Polysomes from control
Table 2. Yields of Polyribosomes from Control and Bupivacaine-Treated Muscle 5 Days after Injection

\begin{tabular}{lc}
\hline $\begin{array}{l}\text { Percentage of } \\
\text { Bupivacaine (wt/vol) }\end{array}$ & $\begin{array}{c}\text { Polysome Yield } \\
\text { (A }_{\mathbf{2 6 0}} / \mathbf{g m} \text { Muscle) }\end{array}$ \\
\hline Control & $6.8 \pm 1.3$ \\
1.50 & $31.3 \pm 7.1$ \\
1.00 & $36.4 \pm 10.5$ \\
0.75 & $27.5 \pm 7.9$ \\
0.50 & $22.4 \pm 5.0$ \\
\hline
\end{tabular}

"Average values $\pm S D$ from 5 separate experiments. Yields from injected muscle differed from control values at $\mathrm{P}<0.001$ for all bupivacaine doses.

muscle and from muscle injected with $1.5 \%$ bupivacaine are compared. The striking result of this experiment is that, per $A_{260}$ unit of polysomes added to the mixture, polysomes from the regenerating muscle are considerably more active than those from control muscle.

Figure $3 \mathrm{~B}$ reveals that this increase in activity of the polysomes is also dependent on the dose of bupivacaine used to inject the muscle. The data in this figure are expressed as $\mathrm{cpm}{ }^{35} \mathrm{~S}$-methionine incorporated into protein $/ \mathrm{A}_{\mathbf{2 6 0}}$ unit of polysomes added to the reaction mixture. As can be seen, at higher doses of bupivacaine, the activity of the polysome preparations is increased.

Activity of Polysomes With Synthetic Messenger RNA. If the data of Figure 3 reflect a real increase in the activity of ribosomes from regenerating muscle, this increase should be manifested when those ribosomes are allowed to translate an exogenously added, synthetic messenger RNA. To test this possibility, polysomes from a control muscle and a muscle injected with $1.5 \%$ bupivacaine were tested for activity with poly $U$ as the messenger RNA. The results of a series of experiments are shown in Figure 4. Polysomes from the bupivacaine-treated muscle were, indeed, more active in supporting poly-U-directed polyphenylalanine synthesis than polysomes from control muscle. It should be noted that the data in this figure represent $\mathrm{cpm}{ }^{3} \mathrm{H}$-phenylalanine incorporated in the presence of poly $\mathrm{U}$ minus cpm incorporated in its absence. Thus, the data have been corrected for endogenous phenylalanine incorporation. In the experiment depicted in Figure 4, polysomes from bupivacaine-treated muscle were about 1.5-fold more active in poly- $U$ translation than control polysomes. In the experiments of Figure 3, polysomes from muscle injected with $1.5 \%$ bupivacaine were $1.7 \times$ more active than controls. These results strongly suggest that the 


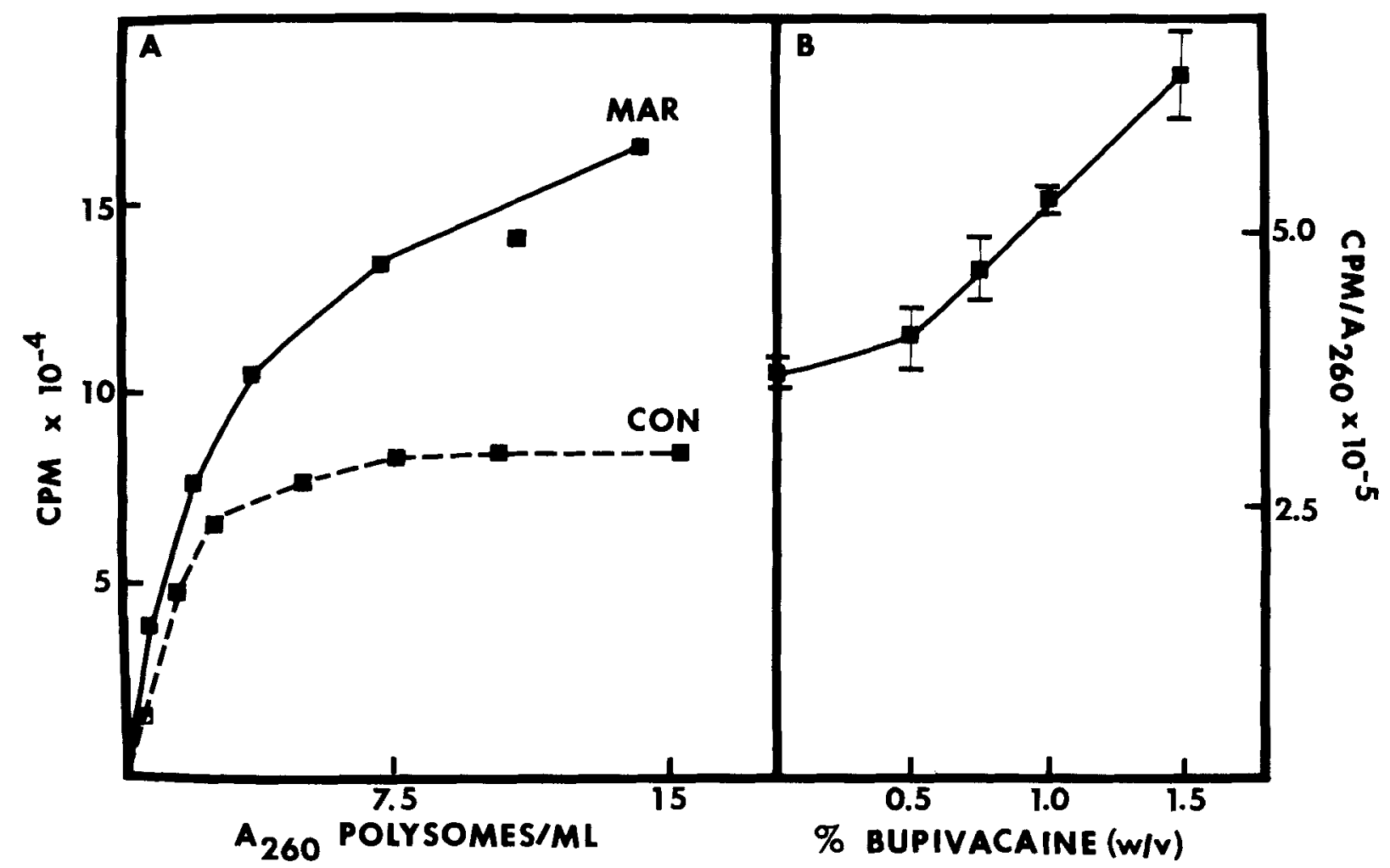

Figure 3. (A) Effects of varying polysome concentrations on the incorporation of ${ }^{35}$ S-methionine in a cell-free system. Incubation conditions were as described in Materials and Methods and varying amounts of polysomes were added to individual reaction mixtures. The solid line represents incorporation by polysomes from muscle injected with $1.5 \%$ bupivacaine, and the dashed line represents incorporation by control polysomes. Results presented are from a single experiment. (B) Specific activity of polysomes isolated from control muscle and muscles injected with varying doses of bupivacaine. Results are expressed as cpm ${ }^{35} S-m e t h i o n i n e$ incorporated $/ A_{260}$ unit of polysomes added to the reaction mixtures. Mixtures contained equal quantities of polyribosomes (4 $\left.A_{260} / m_{1}\right)$. Values are means of 4 experiments $\pm S D$. Specific activities of polysomes from injected muscle differed from controls at $P \pm 0.02$ $(0.5 \%), 0.01(0.75 \%)$, and $0.001(1.0$ and $1.5 \%)$. The control value is shown at zero bupivacaine concentration on the vertical axis.

activity increase depicted in Figure 3 reflects a response to the regeneration process.

\section{Combined Effects of Polysome Yield and Activity on} Muscle Protein Synthesis. The data presented thus far indicate that regenerating muscle may increase its capacity for protein synthesis by increasing the yield and activity of the polyribosomes involved in protein synthesis. It is of interest to determine, therefore, whether the observed in reases in polysome yield and activity can account for the increased protein synthesis observed with muscle fragments (Fig. 2). To this end, the effects of the yield and activity increases have been combined to produce the estimates presented in Table 3. It should be noted that the raw data used to produce the values in Table 3 were averaged results of several experiments. The second column in Table 3 represents the relative increase in protein synthesis in the fragment incubations for muscles injected with each bupivacaine concentration as compared with controls. Thus, muscle fragments from a $1.5 \%$ injection were $10.8 \times$ more active than fragments from the contralateral control. The third column presents the relative increases in polysome yield at each bupivacaine concentration (a $1.5 \%$ injection produces a 4.6-fold increase in yield as compared with controls), and the fourth column shows the relative increase in activity in the cell-free system (a $1.5 \%$ injection leads to a 1.7 -fold increase in activity as compared with controls). The last column represents the products of the values in columns 3 and 4 , the combined effect of the increase in polysome yield and activity. If these two changes are sufficient to account for the increase in protein synthesis observed with muscle fragments, the numbers in the second and fifth columns should be identical. There is certainly some contribution to the values in column 5, due to the experimental errors inherent in the polysome activity and yield 


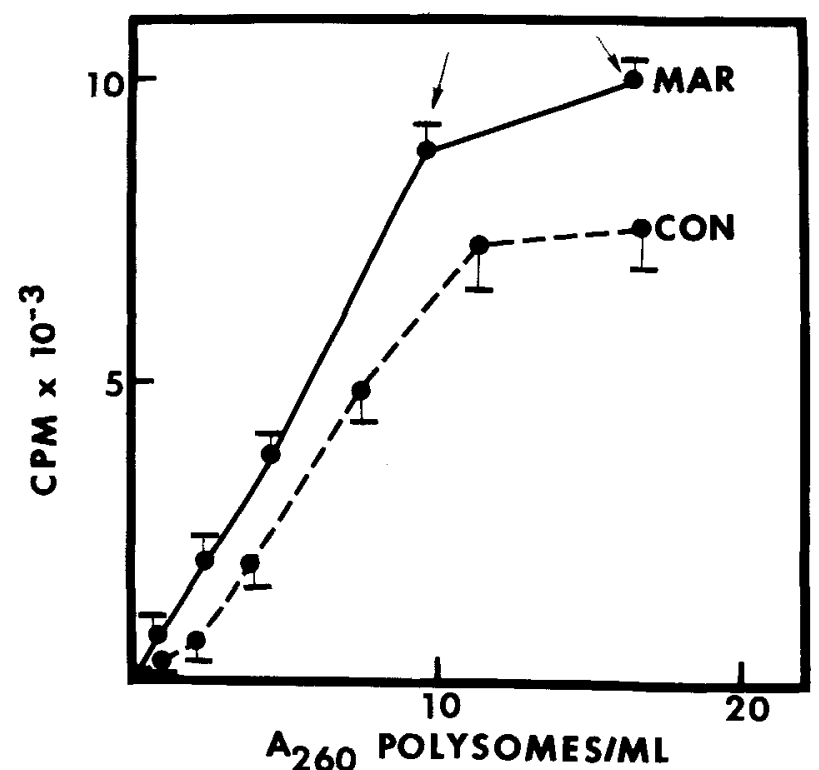

Figure 4. Effects of varying polysome concentrations on the incorporation of $3 \mathrm{H}$-phenylalanine in a poly-U-directed cell-free system. The data in the figure represent the cpm incorporated in the presence of poly $U$ minus the cpm incorporated at the same polysome concentration in the absence of poly $U$, and are averages of three experiments. The arrows indicate points at which the activity of the polysomes from injected muscle differs from the control at $\mathrm{P}<0.05$. The solid line shows incorporation by polysomes from muscle injected with $1.5 \%$ bupivacaine, and the dashed line shows incorporation by control polysomes. Incubation conditions were as described in Materials and Methods.

measurements, and it must be emphasized that the values in the fifth column are only estimates. Nevertheless, a comparison of columns 2 and 5 strongly suggests that the increases in polysome yield and activity in regenerating muscle can ex- plain the increase in protein synthesis observed when fragments of that muscle are incubated with radioactive amino acid.

Spectrum of Proteins Synthesized by Control and Regenerating Muscle. Although the data presented above indicate that changes in the translational apparatus accompany the regeneration process in skeletal muscle, the experiments presented provide no information on the kinds of proteins which are synthesized by regenerates. To determine whether the spectrum of newly synthesized proteins was similar in control and regenerating muscle, aliquots of cell-free reaction mixtures containing muscle polysomes were analyzed by sodium dodecyl sulfate gel electrophoresis on 7 to $15 \%$ linear gradient gels. Results of a typical experiment are shown in the fluorogram of Figure 5. It can be seen that a number of proteins are synthesized in the polysomal cell-free reaction systems, including proteins which migrate with the myosin heavychain and actin standards. Specific quantitation of the relative levels of myosin heavy-chain and actin synthesis is currently in progress in this laboratory using this technique of two-dimensional gel electrophoresis.

\section{DISCUSSION}

Bupivacaine has been shown to be a valuable tool in the study of skeletal muscle regeneration. Benoit and Belt, ${ }^{2}$ Jirmanova and Thesleff ${ }^{9}$ and HallCraggs $^{8}$ have all shown that injection of appropriate concentrations of the drug into skeletal muscle leads to rapid degeneration and regeneration of the muscle tissue. One hundred percent

Table 3. Experimental and Calculated Protein Synthesis Levels in Control and Bupivacaine-Treated Skeletal Muscle

\begin{tabular}{lcccc}
\hline $\begin{array}{l}\text { Percentage of } \\
\text { Bupivacaine } \\
\text { (wt/vol) }\end{array}$ & $\begin{array}{c}\text { Protein Synthesis } \\
\text { Ratio from Frag- } \\
\text { ment Incubations }\end{array}$ & $\begin{array}{c}\text { Polysome } \\
\text { Yield } \\
\text { Ratiot }\end{array}$ & $\begin{array}{c}\text { Polysome } \\
\text { Activity } \\
\text { Ratioł }\end{array}$ & $\begin{array}{c}\text { Calculated Pro- } \\
\text { tein Synthesis } \\
\text { Ratio§ }\end{array}$ \\
\hline Control & 1.0 & 1.0 & 1.0 & 1.0 \\
1.50 & 10.8 & 4.6 & 1.7 & 8.0 \\
1.00 & 6.2 & 5.3 & 1.4 & 7.6 \\
0.75 & 3.9 & 4.0 & 1.3 & 5.1 \\
0.50 & 1.8 & 3.3 & 1.1 & 3.5 \\
\hline
\end{tabular}

${ }^{*}$ Calculated by dividing the com/mg protein from the fragment incubations at each bupivacaine concentration by the control value. Data were taken from Figure 2.

tCalculated by dividing the polysome yields $\left(A_{\mathbf{2 6 0}} / g m\right.$ muscle from Table 2 ) at each bupivacaine concentration by the control value

$\ddagger$ Calculated by dividing the $\mathrm{cpm} / \mathrm{A}_{26 \mathrm{v}}$ from the polysome incubations at each bupivacaine concentration by the control value. Data were obtained from Figure $3 B$.

$\S$ Calculated by multiplying the yield ratio by the activity ratio. Standard deviations and $\mathrm{P}$ values for the raw data used to produce columns 2 to 4 are provided in Figures 2 and 3 and Table 2. 


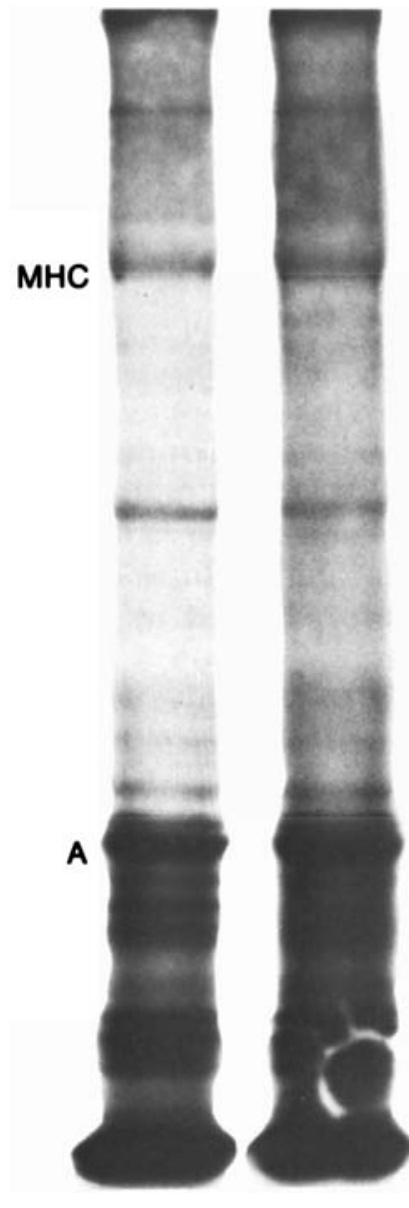

C
1.5

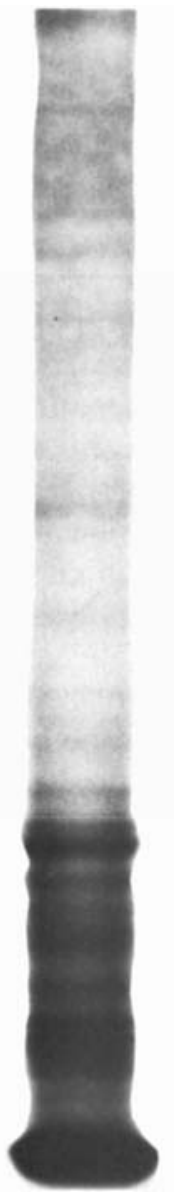

1

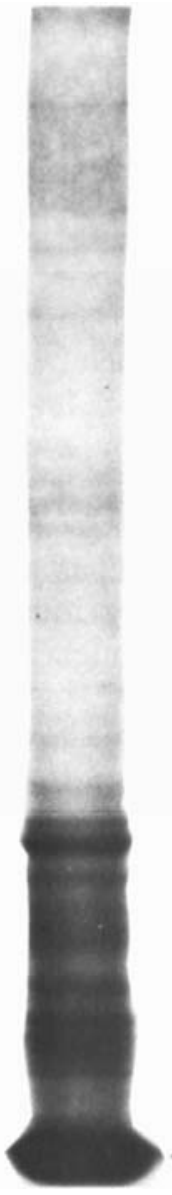

0.75

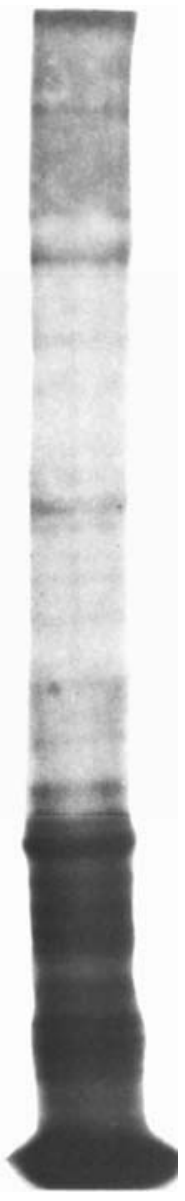

0.5
Figure 5. Gel electrophoresis of proteins synthesized in polysomal cell-free systems. Reaction conditions were as specified in Materials and Methods and samples were electrophoresed on 7 to $15 \%$ linear gradient ge/s. Gels were then subjected to fluorography. ${ }^{3}$ Approximately 20,000 cpm were applied to each lane. $M H C=$ myosin heavy chain, $A=$ actin. Numbers at the bottom of each lane indicate the bupivacaine dose used for injection. regeneration was generally not observed when bupivacaine alone was injected. Carlson and Gutmann ${ }^{7}$ and Wagner et al. ${ }^{17}$ were able to obtain complete destruction of existing muscle fibers, and thus, complete regeneration, by surgical removal of the muscle followed by soaking in bupivacaine solution and reimplantation in the original limb bed. These studies ${ }^{5,6,17}$ have also led to the conclusion that bupivacaine treatment produces a homogenous population of muscle fibers which differentiate synchronously to produce new muscle. Bupivacaine has been exploited as a stimulus for skeletal muscle regeneration in the present study, and it has been shown that an appropriate injection technique can, indeed, lead to essentially complete destruction of existing muscle fibers in the rat tibialis anterior muscle. Thus, the value of this drug in regeneration studies is well established.

The present experiments have also shown that muscle regeneration is accompanied by dramatic changes in the capacity of the muscle for protein synthesis. Fragments of regenerating muscle are much more active than control muscle fragments in incorporating amino acids into protein. Although the fragment incubation may not provide an ideal measure of the protein synthetic capacity of the muscle system, the magnitude of the changes shown in Figure 2 suggest real differences between control and regenerating muscle in terms of that synthetic activity. The increased activity seems to reflect, in part, an increase in the concentration of polyribosomes in the regenerating fibers. The increased polysome concentration presumably results from the increased synthesis of ribosomes, which has been previously reported for regenerating muscle, ${ }^{1,4}$ and may also indicate the synthesis of increased quantities of messenger RNA in regenerates. Preliminary data from this laboratory suggest that there is an increase in the amount of polyadenylated RNA, which is present in bupivacaine-treated, regenerating muscle as 
compared to controls. This result suggests the possibility of transcriptional regulation of protein synthesis during regeneration.

The studies described in this report also indicate that polyribosomes from regenerating muscle are more active in protein synthesis than those from control muscle. Although it is possible that bupivacaine injection affects amino acid transport or pool size in the muscle fiber, the data of Figure 3 argue strongly against the notion that such changes are responsible for the increase in protein synthesis observed with fragments of regenerating muscle (Fig. 2). It should also be noted that the combined effects of the increases in polysome yield and activity are sufficient to explain the increased amino acid incorporation observed with fragments of regenerating muscle. The increase in activity must be due to an effect at the level of the polysomes themselves, since the soluble enzyme fraction used in the cell-free incubations was from a heterologous source (rat liver) and was the same in all experiments. The experiments with synthetic messenger RNA support this contention. In addition, it has been shown that the difference in the activity of polysomes from control and bupivacaine-treated muscles cannot be attributed to the presence of translational inhibitors or ribonuclease in control preparations. Protein synthesis levels were additive when appropriate concentrations of polysomes from control and bupivacaine-injected muscle were mixed, and the addition of human placental ribonuclease inhibitor to polysomal cell-free reaction mixtures had no effect on amino acid incorporation (data not shown). Taken together, these results suggest that the response of the translational apparatus during regeneration may also involve a translational control mechanism. Experiments are in progress to determine whether changes in the ribosomes from regenerating muscle can explain the observations of Figure 3.

As shown in Figure 5, muscle polysomes synthesized a spectrum of proteins, including species with the electrophoretic mobilities of myosin heavy chain and actin. Figure $\mathfrak{5}$ also suggests that the dose of bupivacaine injected can influence the relative amounts of proteins synthesized by muscle polysomes 5 days following injection. The quantitative differences suggested by Figure 5 are not likely to be due to proteolytic artifacts, since the addition of leupeptin and phenylmethylsulfonylfluoride to cell-free reaction mixtures affected neither the activity of the polysomes, nor the elec- trophoretic pattern of the newly synthesized proteins (data not shown).

It is noteworthy, and perhaps a bit surprising, that the magnitude of the response of the translational machinery is proportional to the bupivacaine dose used to induce regeneration. This proportionality was observed with muscle fragments and with polysomes isolated from those fragments (Figs. 2 and 3). It seems unlikely that this doseresponse phenomenon represents a direct effect of the drug on the protein synthetic apparatus, since the response is manifested as late as 5 days following the bupivacaine injection. In addition, earlier experiments suggest that bupivacaine exerts an inhibitory rather than a stimulatory effect on protein synthesis. ${ }^{10,11}$ The dose-response phenomenon more likely reflects the ability of increasing doses of bupivacaine to mobilize increasing proportions of the treated muscle for the regeneration process. If this hypothesis is correct, it could be argued that 1.0 and $1.5 \% \mathrm{wt} / \mathrm{vol}$ bupivacaine should be the doses of choice for the induction of regeneration in the injection model. However, the results shown in Figure 1 indicate that the $1.5 \%$ bupivacaine injection produces a significant level of muscle ischemia. Similar observations were made when $1.0 \%$ bupivacaine was injected (data not shown). Although the extent to which ischemic muscle may participate in regeneration is not known, it seems possible, at the very least, that the presence of large regions of ischemic muscle may destroy the synchrony of regeneration. Since synchronous regeneration is essential to the performance of definitive biochemical studies, the bupivacaine concentration of choice for subsequent studies is $0.75 \%$. At this dose, muscle regeneration is extensive, but little or no muscle ischemia is generally observed.

Experiments are in progress to examine the time course of regeneration in muscles injected with $0.75 \%$ bupivacaine in terms of the effects exerted on the yield and activities of polysomes and the total and polyadenylated RNA.

\section{REFERENCES}

1. Allbrook D: An electron microscope study of regenerating skeletal muscle. J Anat 96:137-153, 1962.

2. Benoit PW, Beit WD: Destruction and regeneration of skeletal muscle after treatment with a local anaesthetic, bupivacaine (Marcaine). J Anat 107:547-556, 1970.

3. Bonner W, Laskey RA: A film detection method for tritium-labelled proteins and nucleic acids in polyacrylamide gels. Eur J Biochem 46:83-88, 1974.

4. Carlson BM: The regeneration of skeletal muscle-A review. Am J Anat 137:1 19-149, 1973. 
5. Carlson BM: A quantitative study of muscle fiber survival and regeneration in normal, predenervated and Marcaine-treated free muscle grafts in the rat. Exp Neurol 52: 421-432, 1976.

6. Carlson BM, Gutmann E: Contractile and histochemical properties of regenerating cross-transplanted fast and slow muscles in the rat. Pfluegers Arch 353:227-239, 1975.

7. Carlson BM, Gutmann E: Free grafting of the extensor digitorum longus muscle in the rat after Marcaine pretreatment. Exp Neurol 53:82-93, 1976.

8. Hall-Craggs ECB: Rapid degeneration and regeneration of a whole skeletal muscle following treatment with bupivacaine (Marcaine). Exp Neurol 43:349-358, 1974.

9. Jirmanova I, Thesleff S: Ultrastructural study of experimental muscle degeneration and regeneration in the adult rat. $Z$ Zellforsch 131:77-97, 1972.

10. Johnson ME, Jones GH: Effects of Marcaine, a myotoxic drug, on macromolecular synthesis in muscle. Biochem Pharmacol 27:1753-1757, 1978.

11. Jones GH: Marcaine, a selective inhibitor of eukaryotic aminoacylation. Biochemistry 18:4452-4457, 1979.

12. Jones GH: Cell-free synthesis of the phenoxazinone synthetase subunit by polyribosomes from Streptomyces antibioticus. J Biol Chem 255:1945-1949, 1980.

13. Laemmli UK: Cleavage of structural proteins during the assembly of the head of bacteriophage T4. Nature 227: $680-685,1970$.

14. Mallette LE, Exton JH, Park CR: Control of gluconeogenesis from amino acids in the perfused rat liver. $J$ Biol Chem 244:5713-5723, 1969.

15. Rogers PA, Jones GH, Faulkner JA: Protein synthesis in skeletal muscle following acute exhaustive exercise. Muscle Nerve 2:250-256, 1979.

16. TeLivuo L; A new long-acting local anaesthetic solution for pain relief after thoracotomy. Ann Chir Gynaecol Fenn 52:513-520, 1963.

17. Wagner KR, Carlson BM, Max SR: Developmental patterns of glycolytic enzymes in regenerating skeletal muscle af ter autogenous free grafting. I Neurol Sci 34:373-390, 1977. 